\title{
Research on Electric Field Optimization of 750kV Double-joint Strain Insulator String Fittings
}

\author{
Yan $\mathrm{Xie}^{1}, \mathrm{Mu} \mathrm{Li}{ }^{2}$, Changzheng Zheng ${ }^{1}$, Zhe Mao ${ }^{1}$ \\ ${ }^{1}$ School of Electrical and Electronic Engineering, Wuhan Polytechnic University, Wuhan, 430023, \\ China \\ ${ }^{2}$ Transmission Department, Wuhan Nari Limited Liability Company of State Grid Electric Power \\ Research Institute, Wuhan 430074, China \\ limimimm@163.com
}

Keywords: Double-joint strain insulator string fittings, Equalizing shielding ring, Electric field.

\begin{abstract}
Double-joint strain insulator fittings are the main equipment substations. It is great significance for reducing its maximum electric field strength to avoid corona noise and to improve substation electromagnetic environment. Firstly double-joint strain insulator string fittings simulation model is given by use of ansys 14.0, and the electric field is simulated and calculated according to the actual installation location of the related equipment. The construction for double-joint strain insulator string fittings is optimized to reduce the electric field value on basis of studying on the simulation significantly higher electric field points. The simulation results show increasing the number of equalizing shielding ring, for reducing the electric field strength of double-joint strain insulator string fittings, is more effective than increasing the diameter of equalizing shielding ring.
\end{abstract}

\section{Introduction}

In recent years, environmental problems have become increasingly prominent. With power grid technology continues to develop and improve, it has become an urgent need to solve the problem to reduce substation's corona and noise, radio interference, electromagnetic induction level. Especially in Xinjiang and northwest interconnected $750 \mathrm{kV}$ power transmission project, the noise problem has become the focus of concern, but also the important and difficult for the fine design.

Preventing corona emergence is one of the means to effectively reducing electromagnetic noise 。 It can effectively prevent the emergence of the corona to let the device's electric field strength lower than the corona inception. Therefore, it is necessary to analyzing device's electric field distribution characteristics. For $750 \mathrm{kV}$ double-joint strain insulator string fittings, in order that reduce the noise caused by its corona, its electric field simulation model is established to study its electric field distribution characteristics in different structural forms in this paper.

\section{Simulation Model of Double-joint Strain Insulator String Fittings}

Considering the accuracy of the calculation and the amount of calculation, its analysis model is established for a double-joint strain insulator string in the middle phase of $750 \mathrm{kV}$ substation gate-shaped frames, based on the actual size of door-shaped frame, insulators, equalizing shield ring and the upper wire. The shapes of connection fittings, the united board and clamp are reasonably simplified.

The relative permittivity ratio of porcelain sheds of the insulator is taken as 6 . All entities are surrounded by two air cubes. The first layer of air just wraps entity, and the second layer of air body is arched. The whole model is shown in Figure 1.

The model of insulators, connector fittings and equalizing shielding ring is established for the intermediate phase portion on which withstand peak voltage Um. Another two-phase only is build conductor models, and respectively is loaded -Um/2 according to the phase sequence. High-voltage 
side of the wire , equalizing shield ring, connecting fittings and steel legs connected thereto in the middle phase is loaded high potential for $U^{\prime} m=653 \mathrm{kV}$. Insulator iron cap of low-voltage side of the wire and gate-shaped frame are loaded 0 potential. Ground and air border outsourcing are loaded 0 potential. Steel foot and iron cap unknown potential are calculated using the coupled degrees of freedom as floating potential conductor.

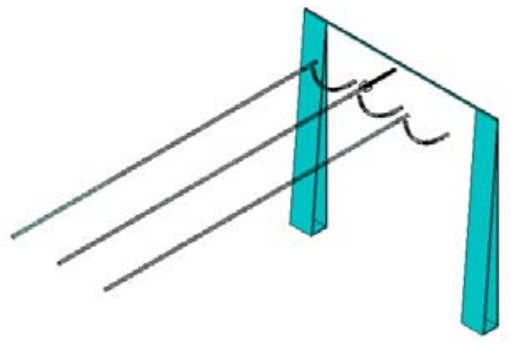

(a) main body model diagram

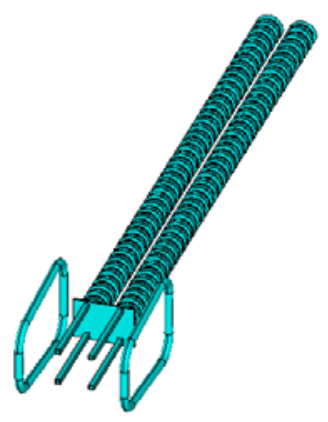

(b) insulator string model diagram

Fig.1 model diagram of double-joint strain insulator string fittings

\section{Electric Field Simulation Results}

\section{Two equalizing shielding ring with the diameter of $100 \mathrm{~mm}$}

When the equalizing shielding ring diameter of the double-joint strain insulator string is $100 \mathrm{~mm}$, electric field simulation contours of equalizing shielding ring and connecting plate are shown in Figure 2.
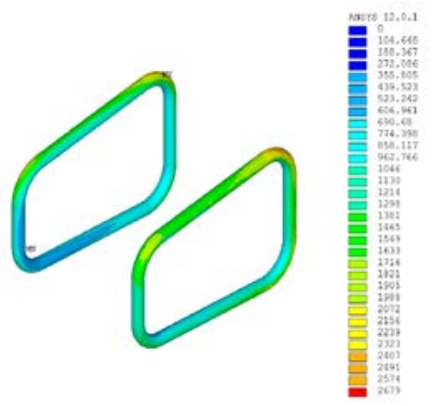

(a) equalizing shielding ring (100mm diameter)

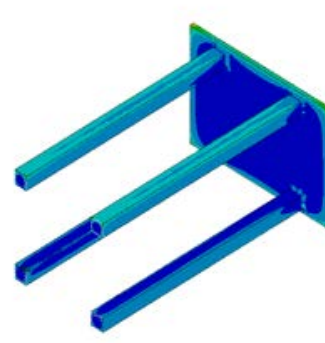

(b)connection plate

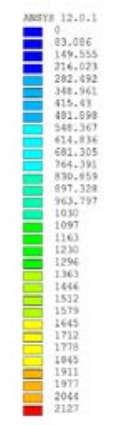

Fig.2 Electric field simulation contours

As can be seen from Figure 2, the maximum field strength of equalizing shield ring surface is $26.79 \mathrm{kV} / \mathrm{cm}$, appearing in the ring at the corner arc. The maximum field strength is connecting plate surface $21.27 \mathrm{kV} / \mathrm{cm}$, appearing in the four corners of the board connecting plate. The maximum field strength value equalizing shielding ring is larger. So it's structure need to be optimized in order to reduce the electric field strength value.

\section{Two equalizing shielding ring with the diameter of $120 \mathrm{~mm}$}

When the equalizing shielding ring diameter of the double-joint strain insulator string is $120 \mathrm{~mm}$, electric field simulation contours of equalizing shielding ring and connecting plate are shown in Figure 3.

As can be seen from Figure 3, the maximum field strength of equalizing shield ring surface is $24.66 \mathrm{kV} / \mathrm{cm}$, appearing on the outside of the ring at the corner arc. The maximum field strength is connecting plate surface $23.68 \mathrm{kV} / \mathrm{cm}$, appearing in the legs of the board connecting plate. The maximum field strength value equalizing shielding ring decreases slightly. So its structure need to be further optimized in order to reduce the electric field strength value. 

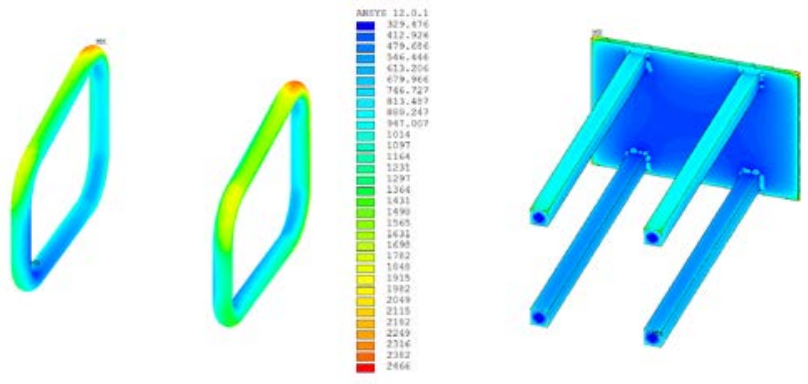

(a) equalizing shielding ring (120mm diameter)

Fig.3 Electric field simulation contours

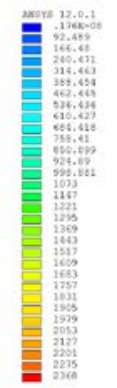

(b)connection plate

\section{Two equalizing shielding ring with the diameter of $150 \mathrm{~mm}$}

When the equalizing shielding ring diameter of the double-joint strain insulator string is $150 \mathrm{~mm}$, electric field simulation contours of equalizing shielding ring and connecting plate are shown in Figure 4.

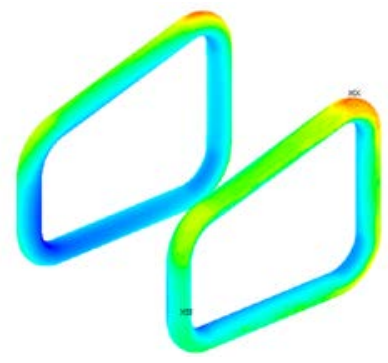

(a) equalizing shielding ring (150mm diameter)

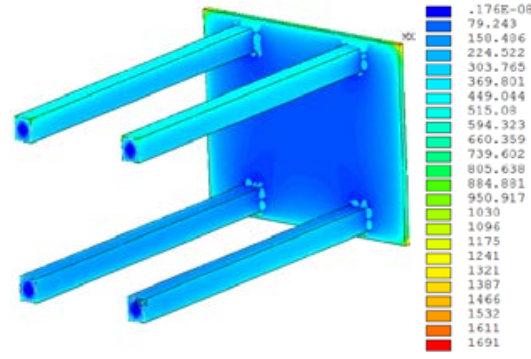

(b)connection plate

Fig.4 Electric field simulation contours

As can be seen from Figure 4, the maximum field strength of equalizing shield ring surface is $21.22 \mathrm{kV} / \mathrm{cm}$, appearing on the outside of the ring at the corner arc. The maximum field strength is connecting plate surface $15.84 \mathrm{kV} / \mathrm{cm}$, appearing in the four corners of the board connecting plate.

As can be seen from the above analysis, with the diameter of equalizing shielding rings from $100 \mathrm{~mm}$ to $150 \mathrm{~mm}$, the maximum field strength value of surface of equalizing shielding ring is significantly reduced. The maximum field strength of equalizing shielding ring drops $21.22 \mathrm{kV} / \mathrm{cm}$ from $26.79 \mathrm{kV} / \mathrm{cm}$, and the field strength decreased by $21 \%$. The maximum field strength of connecting plate drops $16.91 \mathrm{kV} / \mathrm{cm}$ from $21.27 \mathrm{kV} / \mathrm{cm}$, and the field strength decreased by $20 \%$.

\section{Three equalizing shielding ring with the diameter of $100 \mathrm{~mm}$}

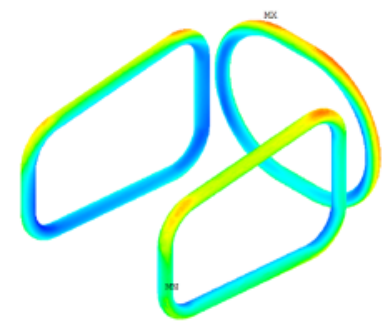

(a) equalizing shielding ring (100mm diameter)

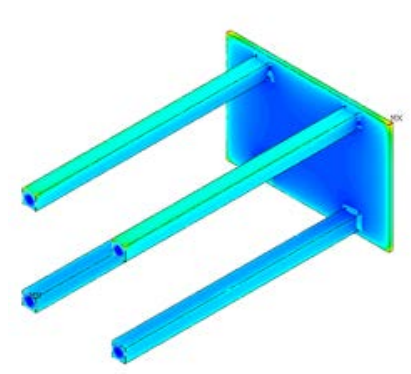

(b)connection plate

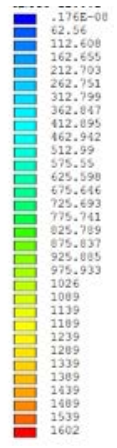

Fig.5 Electric field simulation contours

When three equalizing shielding ring diameter of the double-joint strain insulator string is $100 \mathrm{~mm}$, electric field simulation contours of equalizing shielding ring and connecting plate are shown in Figure 5.

As can be seen from Figure 5, after adding an equalizing ring, the maximum surface field strength of equalizing ring is $19.99 \mathrm{kV} / \mathrm{cm}$, appearing in the corner arc of the ring. The maximum surface field strength of connecting plate is $16.02 \mathrm{kV} / \mathrm{cm}$, appearing in the four corners of the board connecting 
plate. Compared with the maximum surface of two equalizing rings, the maximum surface field strength of fittings is decreased significantly.

Two equalizing shielding ring with the diameter of $120 \mathrm{~mm}$, adding an equalizing shielding ring with the diameter of $100 \mathrm{~mm}$

When three equalizing shielding ring of the double-joint strain insulator string working, electric field simulation contours of equalizing shielding ring and connecting plate are shown in Figure 6.

As can be seen from Figure 6, the maximum surface field strength of equalizing ring is $19.77 \mathrm{kV} / \mathrm{cm}$, appearing at the outer corner arc of the additional ring. The maximum surface field strength of connecting plate is $15.85 \mathrm{kV} / \mathrm{cm}$, appearing in the legs of the connecting plate. It shows the field strength can be reduced by increasing a $100 \mathrm{~mm}$ diameter equalizing ring. However, in some high-altitude areas, it is not able to fully meet the requirements of the control field and need to be further optimized.

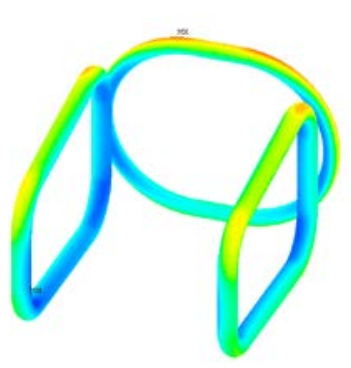

(a) equalizing shielding ring

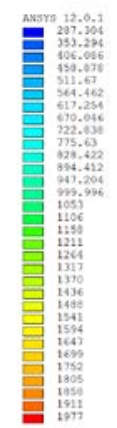

Fig.6 Electric field simulation contours

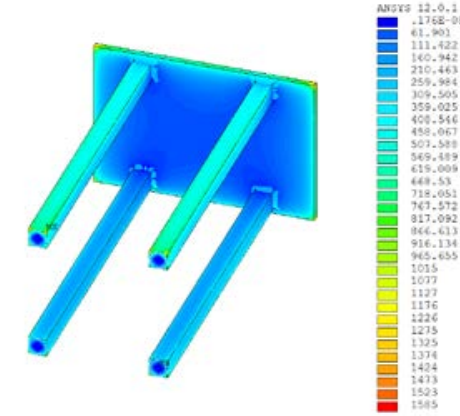

(b)connection plate

\section{Three equalizing shielding ring with the diameter of $120 \mathrm{~mm}$}

When three equalizing shielding ring diameter of the double-joint strain insulator string is $120 \mathrm{~mm}$, electric field simulation contours of equalizing shielding ring and connecting plate are shown in Figure 7.

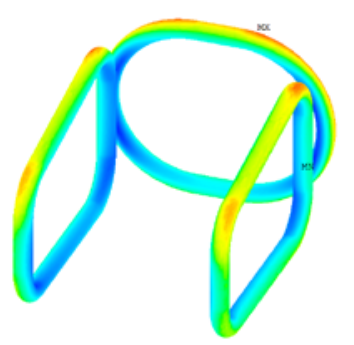

(a) equalizing shielding ring

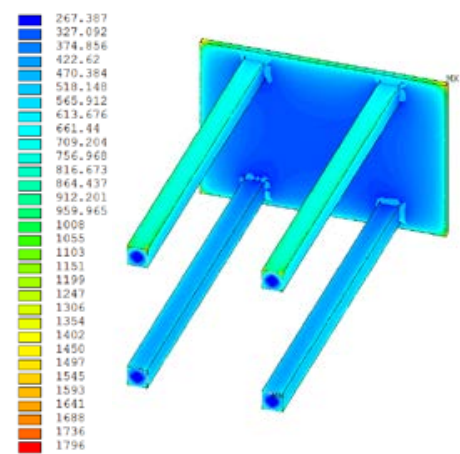

(b)connection plate

Fig.7 Electric field simulation contours

As can be seen from Figure 7, the maximum surface field strength of equalizing ring is $17.96 \mathrm{kV} / \mathrm{cm}$, appearing at the outer corner arc of the additional ring. The maximum surface field strength value of the link plate is $14.84 \mathrm{kV} / \mathrm{cm}$, appearing in the four corners of the board connecting plate. It shows the field distribution has been good improvement when increasing an $120 \mathrm{~mm}$ diameter equalizing ring.

Three equalizing shielding ring with the diameter of $150 \mathrm{~mm}$

When three equalizing shielding ring of the double-joint strain insulator string working, electric field simulation contours of equalizing shielding ring and connecting plate are shown in Figure 8. 


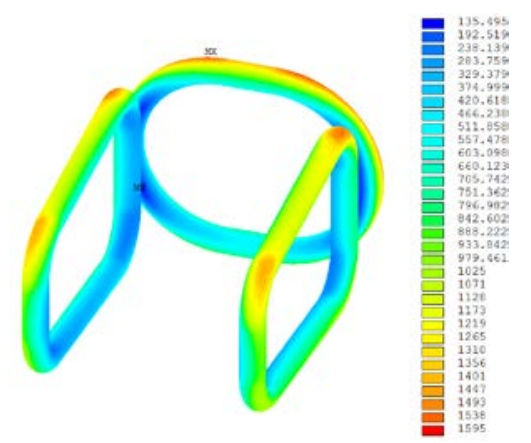

(a) equalizing shielding ring

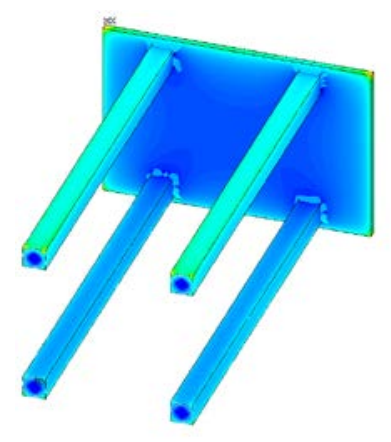

(b)connection plate

Fig.8 Electric field simulation contours

As can be seen from Figure 8, after increasing the equalizing shielding ring with 150mm diameter, the maximum surface field strength of equalizing ring is $15.95 \mathrm{kV} / \mathrm{cm}$, appearing at the outer corner arc of the additional ring. The maximum surface field strength of connecting plate is $13.95 \mathrm{kV} / \mathrm{cm}$, appearing in the four corners of the connecting plate. On the basis of increasing an equalizing ring, increasing the diameter of equalizing rings can make the maximum surface field strength values of fittings obtained more desirable.

The maximum field strength values calculated by increasing the diameter of the equalizing shielding ring is less than the results by adding an equalizing shielding ring. That is, increasing the number of equalizing shielding ring, for reducing the electric field strength, is more effective than increasing the diameter of equalizing shielding ring.

\section{Analysis the Electric Field Optimization for Double-joint Strain Insulator Fittings}

The above simulation results are shown in Table 1.

Table.1 Simulation results of electric field optimization

\begin{tabular}{|c|c|c|c|c|c|}
\hline $\begin{array}{l}\text { Diameter } \\
(\mathrm{mm})\end{array}$ & $\begin{array}{l}\text { Electric } \\
\text { field } \\
\text { Strength } \\
(\mathrm{kV} / \mathrm{cm})\end{array}$ & $\begin{array}{l}\text { optimizing } \\
\text { (adding an } \\
\text { equalizing } \\
\text { ring) }\end{array}$ & $\begin{array}{l}\text { Electric } \\
\text { field } \\
\text { strength } \\
(\mathrm{kV} / \mathrm{cm})\end{array}$ & $\begin{array}{l}\text { optimizing } \\
\text { (adding an } \\
\text { equalizing } \\
\text { ring) }\end{array}$ & $\begin{array}{l}\text { Electric field } \\
\text { Strength } \\
(\mathrm{kV} / \mathrm{cm})\end{array}$ \\
\hline 100 & 26.79 & \multirow{2}{*}{$\begin{array}{l}100 \mathrm{~mm} \\
\text { diameter }\end{array}$} & 19.99 & I & / \\
\hline 120 & 24.66 & & 19.77 & $\begin{array}{l}120 \mathrm{~mm} \\
\text { diameter }\end{array}$ & 17.96 \\
\hline 150 & 21.22 & $\begin{array}{l}150 \mathrm{~mm} \\
\text { diameter }\end{array}$ & 15.95 & / & / \\
\hline
\end{tabular}

From Table 1,we can find when the equalizing shielding ring with $100 \mathrm{~mm}$ diameter of double-joint strain insulator fittings, the maximum field strength were $26.79 \mathrm{kV} / \mathrm{cm}$, appearing in an arc around the corner position. When adding an equalizing shielding ring with $150 \mathrm{~mm}$ diameter on basis of equalizing shielding ring with $150 \mathrm{~mm}$ diameter, the maximum field strength is reduced to $15.95 \mathrm{kV} / \mathrm{cm}$. When adding an equalizing shielding ring with $120 \mathrm{~mm}$ diameter on basis of equalizing shielding ring with $120 \mathrm{~mm}$ diameter, the maximum field strength is $17.96 \mathrm{kV} / \mathrm{cm}$. In practice, the designers should consider the economic, technology and design stress to choose what form the structure should be taken.

\section{Conclusion}

$750 \mathrm{kV}$ substations have most adapted the open layout scheme. Its corona noise sources are more, analysis calculation model is more complex, and noise optimization design is more difficult. This paper analyzes the electric field of $750 \mathrm{kV}$ double-joint strain insulator string fittings to study how to reduce their maximum electric field strength, thereby reducing the possibility of the occurrence of corona and avoiding noise caused by the corona.

The simulation results show increasing the number of equalizing shielding ring, for reducing the electric field strength of double-joint strain insulator string fittings, is more effective than increasing 
the diameter of equalizing shielding ring. In practice, the designers should consider the economic, technology and design stress to choose what form the structure should be taken.

\section{References}

[1] Jingyou Lü, Yu Huang, Aiping ChiI, Leixing Tao, Zhen Chen.The Environmental Influence and Prevention of Transformer-Substations Noise [J] .Power \& Energy, 2011.32(2):162-164.(in Chinese)

[2] WU Xiao-xuan,YANG Ya-ping,LIU Jian,HAN Wei. Measurement and CharacteristicAnalysis ofNoise of 500 kV Substation[J].East China Electric Power, 2010,38(6):0887-0889. (in Chinese)

[3] GUO Tian-lan,WANG Hong-feng,XIAO Xu-liang . Analysis of 220kV Substation Noise Level and Control Measures[J].Shanxi Electric Power, 2011.165(2):7-10. (in Chinese)

[4] ZHOU Jian-fei,ZHOU Nian-guang,YANG Jin-cun,LV Jian-hong,CHEN Shao-yi. Research of Typical Noise Control Technology of Substation in Urban Area[J]. Noise and Vibration Control, 2011.05:173-177. (in Chinese)

[5] XU Lu-wen. Noise Forecast and Optimal Control Design of Out-door Substation[J].Noise and Vibration Control, 2013.02:152-156. (in Chinese)

[6] XU Hao-ming;LIU Xin-shang. Research on Characteristics and Mechanisms of Main Noise SOURCES OF 750kV Substation[J].Journal of Yangling Vocational \& Technical College, 2014.13(2):18-23. (in Chinese).

[7] AN Ran;LU Hailiang;LAN Lei;YUE Yunfeng;TAN Keli;WANG Jianwu;ZHOU Guangyuan. Analysis on Simplified Model and Error of Three-Dimensional Calculation for 3D Electric Field in Substation[J]. Power System Technology, 2014.38(11):3242-3248. (in Chinese)

[8] [8] LI Naiyi,PENG Zongren,DU Jinqiao,FAN Chuanjie. Simulate Calculation and Distribution of Power Frequency Electric Filed in UHV Substation[J].High Voltage Engineering, 2012.38(9):2178-2188. (in Chinese). 